\title{
Erratum to: Immobilized humic substances as redox mediator for the simultaneous removal of phenol and Reactive Red 2 in a UASB reactor
}

Claudia M. Martínez • Lourdes B. Celis •

Francisco J. Cervantes

Published online: 4 October 2013

(C) Springer-Verlag Berlin Heidelberg 2013

Erratum to: Appl Microbiol Biotechnol (2013)

DOI 10.1007/s00253-013-5190-5

The original publication of this paper contains an error. Figure 1 was incorrectly presented and the corrected Figure is as shown below:

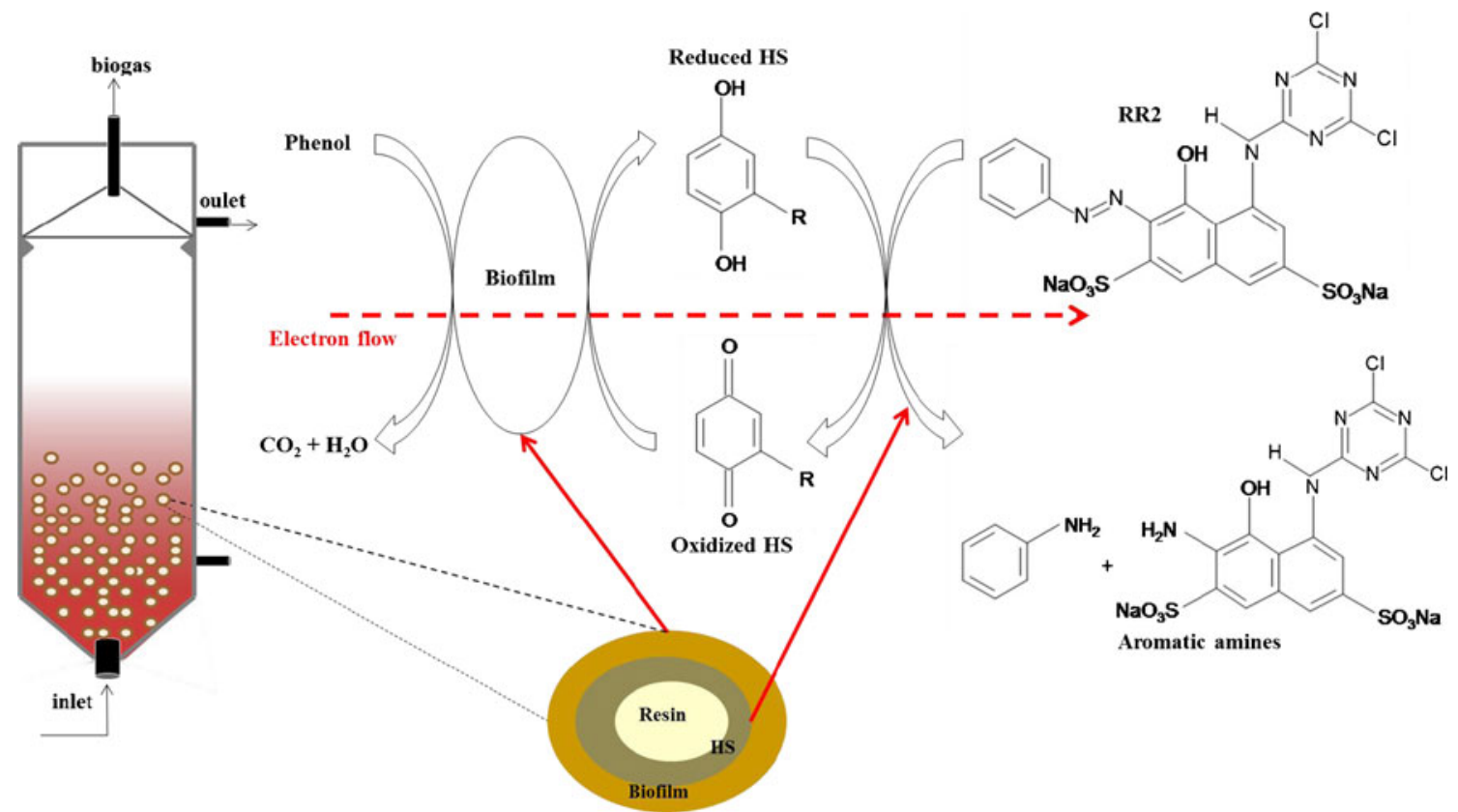

The online version of the original article can be found at http://dx.doi.org/ 10.1007/s00253-013-5190-5.

C. M. Martínez $\cdot$ F. J. Cervantes $(\triangle)$

División de Ciencias Ambientales, Instituto Potosino de Investigación Científica y Tecnológica (IPICYT), Camino a la Presa San José 2055, Col. Lomas 4 a Sección, San Luis Potosí, SLP 78216, Mexico

e-mail: fjcervantes@ipicyt.edu.mx
L. B. Celis

División de Geociencias Aplicadas, Instituto Potosino de Investigación Científica y Tecnológica (IPICYT),

Camino a la Presa San José 2055,

Col. Lomas $4^{\text {a }}$ Sección, San Luis Potosí, SLP 78216, Mexico 